\title{
CONCEITOS SOBRE O MODELO DE CAMPOS E ARMAS DA COMPETIÇÃO
}

\author{
José Celso Contador'
}

\begin{abstract}
Resumo
O modelo de Campos e Armas da Competição (CAC) vem sendo publicado como referencial teórico de muitos estudos, porém, de forma fragmentada. Devido ao grau de consolidação que atingiu, é o momento de publicá-lo na íntegra, a fim de lançá-lo à discussão na comunidade científica da área de Estratégia. É um modelo da Teoria da Competitividade validado cientificamente, que, por ser qualitativo e quantitativo, tem vantagens em relação ao modelo de Porter, RBV e Balanced Scorecard. Ele nasceu de uma idéia simples: separar, de acordo com o interesse do cliente, as chamadas vantagens competitivas, distinguindo as que lhe interessam das que não the interessam. As primeiras referem-se aos campos da competição, e, as segundas, às armas da competição. Os campos da competição estão relacionados à estratégia competitiva de negócio, e as armas da competição às estratégias competitivas operacionais. Este é o primeiro artigo de uma série de três.
\end{abstract}

Palavras-chave: Vantagem Competitiva. Campo da Competição. Arma da Competição. Estratégia Competitiva de Negócio. Estratégia Competitiva Operacional.

Para a concepção do modelo de Campos e Armas da Competição foi necessária uma extensa pesquisa bibliográfica e várias centenas de pesquisas empíricas, cujos resultados permitiram aprofundar os conceitos sobre competitividade. A evolução dos conceitos teóricos iniciais resultou na concepção de um modelo muito bem estruturado, simultaneamente qualitativo e quantitativo, cientificamente validado e que apresenta vantagens em relação aos já existentes.

Os estudos têm gerado artigos que, devido à originalidade, são freqüentemente publicados em revistas científicas e em congressos. Mesmo mostrando apenas fragmentos do modelo, esses artigos conseguiram despertar o interesse da comunidade acadêmica.

' Doutor em Engenharia Mecânica pela Escola de Engenharia de São Carlos, EESC/USP. Endereço: Av. Francisco Matarazzo, 612, Andar térreo, Bairro Água Branca, São Paulo, SP. CEP 0500 I-100. E-mail: celsocontador@terra.com.br. Artigo Recebido em: 04/02/2007. Aceito em: 24/06/2008. Membro do Corpo Editorial Científico responsável pelo processo editorial: Prof. Martinho Isnard Ribeiro de Almeida. 
É o momento de disseminá-lo na íntegra, o que contribuirá para a expansão da pesquisa sobre como as empresas competem e como podem aumentar a sua competitividade.

\section{PRIMEIRAS NOÇÕES SOBRE O MODELO}

Para a empresa ser competitiva, não há condição mais relevante do que ter alto desempenho apenas naquelas poucas armas que lhe dão vantagem competitiva nos campos da competição escolhidos para cada par produto/mercado.

\subsection{A tese do modelo de Campos e Armas da Competição (CAC)}

Muitos afirmam, corretamente, que a empresa não pode ou não deve procurar ser excelente em tudo, mas não especificam em que precisa ser excelente. Especificar claramente onde a empresa precisa ter alto desempenho é uma das vantagens do modelo CAC.

É a epígrafe acima que dá o critério para definir onde a empresa precisa ter alto desempenho e para formular sua estratégia competitiva de negócio e suas estratégias competitivas operacionais.

Quatro conceitos estão explícitos na epígrafe: campos da competição, armas da competição, par produto/mercado e vantagem competitiva. Os três primeiros estão explicados neste artigo; vantagem competitiva será explicada no segundo artigo da série.

A epígrafe retrata a tese do modelo CAC e evidência seu pensamento central. É essa tese que dá força ao modelo, exatamente porque mostra à empresa o caminho a ser trilhado. Devido à sua importância, esse pensamento foi formulado como tese exatamente para caracterizar a necessidade de ser verificada a sua validade. E de fato ela foi validada, como será exposto no próximo artigo.

\subsection{Evolução, objetivo e natureza do modelo CAC}

Os conceitos iniciais do modelo CAC, tendo como pano de fundo a indústria, foram lançados à discussão acadêmica em dois artigos publicados na Revista de Administração da USP em 1995 (CONTADOR, 1995a e 1995b). Posteriormente, foram publicados em dois capítulos de Modelo para aumentar a competitividade industrial (CONTADOR, 1996) e em um capítulo de Gestão de Operações (CONTADOR, 1998).

Desde 1995, esses conceitos evoluíram muito graças às pesquisas realizadas em empresas de diversos segmentos econômicos, e transformaram-se num modelo bastante adequado. Suas várias aplicações, expostas na próxima subseção, têm sido bem-sucedidas tanto em empresas industriais quanto nas de serviços. 
Deve-se destacar que o modelo CAC é qualitativo e quantitativo (quantitativo porque trabalha com variáveis matemáticas). Essas duas características dão-lhe vantagens sobre outros modelos da Teoria da Competitividade que são meramente qualitativos.

\subsection{Aplicações do modelo de Campos e Armas da Competição}

O modelo tem sido utilizado para:

1. Entender, analisar e explicar como um grupo de empresas pertencentes ao mesmo segmento econômico competem entre si.

2. Entender, analisar e explicar a posição competitiva de uma empresa.

3. Diagnosticar as deficiências e identificar as características competitivas de uma empresa.

4. Propor medidas para aumentar a competitividade de uma empresa.

5. Formular a estratégia competitiva de negócio de uma empresa.

6. Formular as estratégias competitivas operacionais de uma empresa.

7. Alinhar as estratégias competitivas operacionais à estratégia competitiva de negócio.

8. Determinar as competências essenciais e o core business de uma empresa.

\section{CONCEITOS E DEFINIÇÃO DE CAMPO E DE ARMA}

Inicialmente, é necessário definir campo da competição e arma da competição, e dar o significado da competição em cada um dos 14 campos da competição.

\subsection{Conceitos, definição e configuração dos campos da competição}

O modelo CAC nasceu de uma idéia simples: separar, de acordo com o interesse do cliente, as chamadas vantagens competitivas, distinguindo as que the interessam das que não lhe interessam. As primeiras referem-se aos campos da competição, e as segundas, às armas da competição.

Para ilustrar o conceito, as seis seguintes vantagens competitivas são normalmente encontradas na bibliografia: preço, propaganda, qualidade do produto, produtividade, variedade de modelos e rapidez de produção. Quais delas interessam ao cliente?

Obviamente, o cliente se interessa por preço, qualidade do produto e variedade de modelos. Essas vantagens competitivas são as relacionadas aos campos da competição. 
Assim, pode-se definir: Campo da competição é o locus imaginário da disputa entre empresas pela preferência do cliente ao produto elou a empresa. Pode também ser definido como o locus imaginário onde a empresa busca alcançar e manter vantagem competitiva.

São 14 os campos da competição. Ou seja, há 14 maneiras básicas (além de suas inúmeras combinações) da empresa se diferenciar, maneiras relativas às características de seu produto e às suas próprias características.

A configuração dos campos da competição representa 14 campos agregados em cinco macrocampos e está exposta no Quadro 1. Para entendê-lo, é conveniente definir: Competir num campo significa ser, ou almejar ser, melhor do que as concorrentes nesse campo da competição; ser a empresa líder nesse campo da competição.

\begin{tabular}{|c|c|}
\hline \multicolumn{2}{|r|}{ Significado de competir em cada campo da competição } \\
\hline $\begin{array}{l}\text { Campos da } \\
\text { competição }\end{array}$ & Significado \\
\hline \multicolumn{2}{|r|}{ Macrocampo Preço } \\
\hline Preço & Ter, ou almejar ter, preço menor do que o preço dos produtos concorrentes. \\
\hline $\begin{array}{l}\text { Condições de } \\
\text { pagamento }\end{array}$ & $\begin{array}{l}\text { Oferecer, ou almejar oferecer, mais facilidades de pagamento do que os } \\
\text { concorrentes, em termos de desconto, prazo, quantidade de parcelas de } \\
\text { pagamento e instrumento de crédito. }\end{array}$ \\
\hline $\begin{array}{l}\text { Prêmio e/ou } \\
\text { promoção }\end{array}$ & $\begin{array}{l}\text { Oferecer, ou almejar oferecer, temporariamente ao comprador, vantagens mais } \\
\text { interessantes do que as dos concorrentes, como sorteios e ofertas, sem alterar o } \\
\text { preço normal de venda. }\end{array}$ \\
\hline \multicolumn{2}{|r|}{ Macrocampo Produto (bem ou serviço) } \\
\hline $\begin{array}{l}\text { Projeto do } \\
\text { produto }\end{array}$ & $\begin{array}{l}\text { Desenvolver, ou almejar desenvolver, produto com características e atributos } \\
\text { valorizados pelos clientes ou consumidores que atendam às suas exigências, } \\
\text { necessidades, preferências, expectativas ou anseios de forma mais atraente que as } \\
\text { características dos produtos concorrentes em termos de aparência visual, funções } \\
\text { a cumprir, facilidade de uso, qualidade dos materiais e do acabamento e outros. }\end{array}$ \\
\hline $\begin{array}{l}\text { Qualidade do } \\
\text { produto }\end{array}$ & $\begin{array}{l}\text { Oferecer, ou almejar oferecer, produto que o cliente julgue de melhor qualidade } \\
\text { do que a dos produtos concorrentes nos mais diversos critérios por ele } \\
\text { valorizados, como aparência visual, funções a cumprir, desempenho, facilidade } \\
\text { de uso, qualidade dos materiais e do acabamento, durabilidade e outros. }\end{array}$ \\
\hline $\begin{array}{l}\text { Diversidade de } \\
\text { produto }\end{array}$ & $\begin{array}{l}\text { Oferecer, ou almejar oferecer, maior variedade de produtos do que os } \\
\text { concorrentes. }\end{array}$ \\
\hline \multicolumn{2}{|r|}{ Macrocampo Atendimento } \\
\hline $\begin{array}{l}\text { Acesso ao } \\
\text { atendimento }\end{array}$ & $\begin{array}{l}\text { Proporcionar, ou almejar proporcionar, melhor acesso ao atendimento do que o } \\
\text { dos concorrentes, sob o ponto de vista do cliente. }\end{array}$ \\
\hline
\end{tabular}




\begin{tabular}{|l|l|}
\hline $\begin{array}{l}\text { Projeto do } \\
\text { atendimento }\end{array}$ & $\begin{array}{l}\text { Desenvolver,oualmejardesenvolver,atendimentocomcaracterísticas valorizadas } \\
\text { pelos clientes que atendam às suas exigências, necessidades, preferências, } \\
\text { expectativas ou anseios de forma mais atraente do que as características do } \\
\text { atendimento das empresas concorrentes. }\end{array}$ \\
\hline $\begin{array}{l}\text { Qualidade do } \\
\text { atendimento }\end{array}$ & $\begin{array}{l}\text { Oferecer, ou almejar oferecer, atendimento que o comprador julgue de melhor } \\
\text { qualidade do que a das empresas concorrentes. (Atendimento refere-se à } \\
\text { recepção, ao contato e à comunicação com o cliente). }\end{array}$ \\
\hline \multicolumn{2}{|c|}{ Macrocampo Prazo } \\
\hline $\begin{array}{l}\text { Prazo de entrega } \\
\text { do produto }\end{array}$ & $\begin{array}{l}\text { Ofertar, ou almejar ofertar, prazo de entrega do produto menor do que o dos } \\
\text { concorrentes e conseguir cumprir o prazo negociado. }\end{array}$ \\
\hline $\begin{array}{l}\text { Prazo de } \\
\text { atendimento }\end{array}$ & $\begin{array}{l}\text { Atender, ou almejar atender, o cliente em prazo menor do que o dos concorrentes. } \\
\text { (O ato de atender refere-se à recepção, ao contato e à comunicação com o cliente). }\end{array}$ \\
\hline \multicolumn{2}{|c|}{ Macrocampo Imagem } \\
\hline $\begin{array}{l}\text { Imagem do } \\
\text { produto e da } \\
\text { marca }\end{array}$ & $\begin{array}{l}\text { Oferecer, ou almejar oferecer, produto que o cliente julgue ter melhor imagem } \\
\text { do que a dos produtos concorrentes e possuir, ou almejar possuir, imagem crível } \\
\text { do produto e da marca mais favorável do que a dos concorrentes, num aspecto } \\
\text { valorizado pelos clientes. }\end{array}$ \\
\hline $\begin{array}{l}\text { Imagem de } \\
\text { empresa } \\
\text { confiável }\end{array}$ & $\begin{array}{l}\text { Possuir, ou almejar possuir, imagem crível mais favorável do que a dos } \\
\text { concorrentes, num aspecto valorizado pelos clientes, funcionários, fornecedores, } \\
\text { membros da sociedade, acionistas e investidores. }\end{array}$ \\
\hline $\begin{array}{l}\text { Imagem em } \\
\text { responsabilidade } \\
\text { social }\end{array}$ & $\begin{array}{l}\text { Possuir, ou almejar possuir, imagem crível em responsabilidade social (quanto } \\
\text { à comunidade, cidadania e meio ambiente) mais favorável do que a dos } \\
\text { concorrentes, num aspecto valorizado pelo cliente. É composto pela imagem } \\
\text { cívica e imagem preservacionista. }\end{array}$ \\
\hline
\end{tabular}

Quadro 1 - Significado de competir em cada campo da competição

Fonte: Elaborado pelo autor.

\subsection{Conceitos e definição de arma e de arma da competição}

Retomando o exemplo anterior, deduz-se por exclusão que o cliente não se interessa por propaganda, produtividade e rapidez de produção. Nada o cliente aproveita em saber se a empresa opera com alta ou com baixa produtividade (muitas pessoas nem sabem o que é produtividade e não precisam, efetivamente, saber); interessa-lhe, sim, o preço do produto. É importante para ele a imagem de um produto criada pela propaganda, mas a propaganda em si não lhe interessa. Seu interesse não está na rapidez de produção, mas no prazo de entrega: não lhe interessa saber se o prazo curto de entrega de um produto decorre de uma produção rápida ou do alto estoque da empresa.

A característica central das armas da competição é não interessar ao cliente. Assim, essas três vantagens são armas da competição 
Podem-se agora definir arma e arma da competição. Arma é qualquer atividade ou recurso da empresa. Arma da competição é uma atividade executada ou um recurso utilizado pela empresa para conquistar elou manter vantagem competitiva.

O critério para saber se uma vantagem é um campo ou uma arma da competição é o interesse do cliente. Se ele tiver interesse, é um campo. Se não tiver, é uma arma.

São armas, por exemplo: SAC - Serviço de Atendimento ao Consumidor, publicidade, comunicação visual, melhoramento contínuo no processo produtivo, manutenção de equipamento, CEP - Controle Estatístico de Processo, recursos financeiros, monitoramento dos concorrentes, elaboração de projeto, equipamentos de produção, treinamento de pessoal e redução de despesas operacionais. Contam-se às dezenas as armas de uma empresa.

Importante ressaltar que uma mesma arma serve para competir em mais de um campo, e para competir em um campo são necessárias várias armas.

De um modo geral, não se distingue o que o modelo CAC conceitua como campo da competição e como arma da competição - eles são tratados sempre como vantagens competitivas. Essa distinção feita pelo modelo CAC facilita sobremaneira a formulação e implementação das estratégias competitivas da empresa, pois campos da competição referem-se à estratégia competitiva de negócio; e armas da competição, às estratégias operacionais.

\section{O MODELO DE CAMPOS E ARMAS DA COMPETIÇÃO E OUTRAS TEORIAS}

Para que o leitor possa situar o modelo de Campos e Armas da Competição é interessante classificá-lo segundo três tipologias e compará-lo com outras teorias.

\subsection{O modelo de Campos e Armas da Competição na tipologia da estratégia}

Para Igor Ansoff (1988), um dos pioneiros em estratégia empresarial, há dois tipos básicos de estratégia: estratégia de carteiras e estratégia competitiva. Por essa tipologia, o modelo CAC se enquadra na estratégia competitiva.

Segundo as quatro abordagens genéricas de estratégia apresentadas por Whittington (2001), o modelo CAC está associado à abordagem clássica, pois entende a estratégia como um processo racional e deliberado cujo objetivo é maximizar a vantagem a longo prazo.

Segundo a classificação de Mintzberg et al. (2000) o modelo pertence à Escola do Posicionamento, pois formula as estratégias por meio de um processo analítico e prescritivo.

De certa maneira, as idéias do modelo CAC assemelham-se às da Visão Baseada em Recursos (RBV - Resource-Based View), pois ela prega que a empresa pode 
criar vantagens competitivas a partir de seus recursos, tornando-se mais lucrativa (PETERAF, 1993; KROGH; ROSS, 1995; BARNEY, 1986a; 1986b; 1991; 2001).

O modelo CAC, além de ser qualitativo, assenta-se em variáveis matemáticas (que são expostas no segundo artigo da série). Assim, segue a tendência recente de privilegiar modelos quantitativos, tendência observada nos trabalhos publicados nos principais periódicos internacionais especializados em estratégia (PRAHALAD; HAMEL, 1994).

Para Markides (1999), a essência da estratégia é a seleção de uma posição que a empresa pode sustentar. O modelo CAC parte desse mesmo entendimento, separando entretanto o posicionamento em duas vertentes: a do produto e a da empresa.

\subsection{O modelo CAC, Porter, RBV e Balanced Scorecard}

O modelo CAC alia duas concepções bastante distintas e que têm sido tratadas isoladamente: a concepção de que a competitividade da empresa provém basicamente do seu posicionamento no mercado, como pensa Porter (1980); e a concepção de que ela provém basicamente dos seus fatores internos, como postulam os autores adeptos da Visão Baseada em Recursos (Resource-Based View - RBV).

Tanto para o Balanced Scorecard (KAPLAN; NORTON, 1992; 1993; 1996; 1997) quanto para o modelo CAC, o alinhamento das estratégias é fundamental para o sucesso da empresa. Mas, o modelo tem se mostrado mais eficiente do que o BSC para alinhá-las porque, devido à sua metodologia, as estratégias operacionais já nascem alinhadas a estratégia competitiva de negócio, tornando dispensável o esforço de alinhamento proposto pelo BSC.

Para um entendimento inicial e superficial do modelo pode-se imaginá-lo como uma junção de alguns conceitos do modelo de Porter com alguns do RBV e do BSC.

O ambiente externo, onde está a ênfase do modelo de Porter, relaciona-se aos campos da competição: 1) formular a estratégia competitiva de negócio é definir produtos para cada mercado e escolher os campos da competição de cada produto em cada mercado; e 2) a estratégia de posicionamento do produto e da própria empresa no mercado é conseguida pela escolha dos campos da competição em cada par produto/mercado.

$\mathrm{O}$ ambiente interno, onde está a ênfase do RBV, relaciona-se às armas da competição - formular as estratégias competitivas operacionais é escolher as armas a serem utilizadas na competição e definir a sua intensidade. $\mathrm{O}$ alinhamento das armas aos campos da competição, que decorre naturalmente da concepção do modelo, é equivalente a idéia central do Balanced Scorecard relativa ao alinhamento das estratégias competitivas da empresa. 


\section{IDENTIFICAÇÃO, VALIDADE, UNIVERSALIDADE, CONSISTÊNCIA,} COMPLETUDE E FLEXIBILIDADE DA CONFIGURAÇÃO DOS CAMPOS

Antes de avançar sobre outros conceitos de campos da competição, cinco questões precisam ser examinadas:

1) Como os campos da competição foram identificados?

2) A configuração dos campos da competição foi validada?

3) Ela é universal, isenta de contradições e completa?

4) Por que exatamente 14 campos e não outra quantidade?

5) A configuração é flexível para se adaptar a qualquer situação?

\subsection{Identificação dos campos da competição}

Os campos foram identificados por meio de longa pesquisa sobre as formas utilizadas pelas empresas para competir, que se iniciou em 1990 e só terminou em 2007. A partir de 1999, a pesquisa se intensificou a ponto de se constituir na principal atividade do autor. Essa pesquisa foi bibliográfica, não apenas na literatura especializada mas também nos casos relatados na imprensa, e, foi também de campo, envolvendo 471 empresas.

4.2 Validade, universalidade, consistência e completude da configuração dos campos

A discussão sobre esses temas está no segundo artigo da série, mas podem-se adiantar algumas conclusões. A configuração dos campos foi validada, é universal. Ela é isenta de contradições, portanto, consistente. Entretanto, supondo que o Teorema de Gödel (NAGEL e NEWMAN, 1958) fosse aplicável ao caso, a configuração, por possuir as propriedades da consistência, não goza das propriedades da completude, no sentido de ser completa e acabada. Ou seja, novos campos poderão surgir - e surgirão quando um novo atributo do produto ou da empresa passar a ser valorizado pelo cliente.

\subsection{Nível de agregação e flexibilidade da configuração dos campos da competição}

A configuração atual dos campos pode variar em função do nível de agregação adotado. Poder-se-ia, por exemplo, desagregar o campo competição em responsabilidade social em dois campos: em imagem preservacionista e em imagem cívica. Poder-se-ia agregar, também como exemplo, o acesso ao atendimento ao campo projeto do atendimento. 
A flexibilidade da configuração não diz respeito apenas à quantidade dos campos, mas também à sua denominação. $\mathrm{O}$ nome de qualquer um dos campos da competição pode, e em algumas situações deve, ser adaptado ao caso em que está sendo aplicado.

Sendo, pois, a flexibilidade uma das propriedades da configuração dos campos da competição, ela se adapta bem a qualquer situação.

Apesar de a configuração dos campos da competição ter sofrido algumas alterações ao longo do tempo, nenhuma delas descaracterizou a estrutura básica dos cinco macrocampos.

Assim, a quantidade de 14 campos é a adotada porque é adequada aos propósitos do modelo CAC. Se sua quantidade fosse muito menor, o modelo ficaria muito vago e perderia sua capacidade de especificar com clareza os campos em que a empresa pode se diferenciar das concorrentes (poderia cair no extremo de haver apenas o campo diferenciação - e a recomendação seria simplesmente a de que a empresa deve encontrar uma posição diferente em relação às concorrentes, sem especificar claramente onde se distinguir).

\section{CAMPO COADJUVANTE E PRODUTO COADJUVANTE}

Outro conceito importante do modelo CAC é o de campo coadjuvante.

\subsection{Conceitos e definição de campo coadjuvante}

Até aqui, tratou-se apenas do campo da competição. Mas há outro tipo de campo, o coadjuvante.

Campo da competição é o campo no qual a empresa vai efetivamente criar ou manter vantagem competitiva. Nele vai efetivamente competir, criando no cliente a imagem de ser melhor do que as concorrentes nesse campo.

Campo coadjuvante é o campo que complementa a estratégia competitiva de negócio da empresa. É um campo auxiliar, mas não um campo da competição - com ele a empresa não compete, mas ele contribui para o alcance e a manutenção das suas vantagens competitivas. Uma empresa pode eleger o projeto do produto e a qualidade do produto como seus campos da competição e qualidade de atendimento e imagem do produto e da marca como coadjuvantes.

Assim, pode-se definir campo coadjuvante como o locus imaginário secundário e complementar da disputa entre empresas pela preferência do cliente ao produto el ou a empresa. É no locus imaginário que a empresa alternativamente busca alcançar e manter vantagem competitiva.

Os campos coadjuvantes são os mesmos 14 campos da competição, agrupados nos mesmos cinco macrocampos. 
As pesquisas têm evidenciado que é comum as empresas de um mesmo segmento econômico competirem no campo mais valorizado pelos clientes. Assim, elas adotam o mesmo campo da competição, o que lhes dá pequena diferenciação. Nesse caso, como elas se diferenciam em relação às concorrentes? Elas se diferenciam pela escolha de diferentes campos coadjuvantes. Veja-se a indústria automobilística. Quase todos os automóveis competem em projeto do produto e em qualidade do produto. Por isso, eles são tão parecidos na opinião do cliente. A disputa pela preferência do comprador desloca-se então do campo da competição para o campo coadjuvante - uma empresa procura proporcionar melhor atendimento pós-venda; outra, melhores condições de pagamento; uma terceira lança mão da distribuição de prêmio ou da realização de promoção; uma quarta procura criar uma imagem que seja valorizada pelo seu público-alvo.

Enfim, é pela escolha de diferentes combinações entre os campos da competição e campos coadjuvantes que as empresas se diferenciam entre si quanto às características dos produtos e/ou quanto às da própria empresa. Geralmente, a empresa compete em um ou dois campos, complementados por um ou dois campos coadjuvantes.

\subsection{Produto e produto coadjuvante}

Produto é o resultado de um processo produtivo ou da execução de um trabalho. Pode ser tangível (como automóvel, sapato, arroz) ou intangível (como filme cinematográfico, consulta médica, conserto de um aparelho eletrodoméstico). Para o modelo de Campos e Armas da Competição, tanto um bem quanto um serviço são denominados produto.

Produto coadjuvante é um produto acessório ou complementar agregado ao produto principal que aumenta o valor atribuído pelo cliente ao produto principal. Revendedores de café gourmet em grão oferecem a máquina de preparo de café expresso aos restaurantes e bares que compram o grão. O produto é o café; o coadjuvante, a máquina. No setor de serviços, esse conceito reflete a máxima: serviços vendem produtos e produtos vendem serviços.

O produto coadjuvante pode ser tanto um bem quanto um serviço e pode ser agregado tanto a um bem quanto a um serviço. Portanto, há quatro combinações possíveis: 1) agregar um bem a outro; 2) um serviço a um bem; 3) um serviço a outro; e 4) um bem a um serviço.

Utilizar um produto coadjuvante é uma estratégia comumente adotada pelas empresas, pois pode ser um fator importante na decisão de compra do cliente, pode determinar a preferência do cliente pelo produto principal. E, não raras vezes, é uma fonte de receita extra. 


\section{SEGMENTAÇÃO DE MERCADO E O PAR PRODUTO/MERCADO}

\subsection{Conceitos e definição de Segmentação do mercado}

São raros os casos de produtos que atendem o mercado na sua totalidade, como aparelho de barbear, lápis e refrigerante; pois de um modo geral os clientes, tanto os consumidores quanto os organizacionais, têm distintas exigências, necessidades, preferências, expectativas ou anseios. Para poder atender satisfatoriamente os clientes, a empresa precisa identificar segmentos desse mercado amplo.

Provavelmente quem primeiro definiu Segmentação de mercado foi Smith (1956): Segmentação de mercado é uma adequação do produto e do esforço de marketing às exigências do consumidor ou usuário pela partição de um mercado heterogêneo, de necessidades diferentes em vários mercados homogêneos.

Para o modelo CAC, Segmentação de mercado é o processo de identificação de um grupo de clientes que tenham exigências, necessidades, preferências, expectativas ou anseios similares em relação ao produto da empresa. Ou seja, é o processo de identificação de uma parte mais homogênea de um mercado maior e heterogêneo. Obviamente, a finalidade da Segmentação de mercado é satisfazer melhor essas especificidades dos clientes.

A Segmentação de mercado é alcançada por meio de três etapas seqüenciais: $\left.1^{a}\right)$ identificação e avaliação das exigências, necessidades, preferências, expectativas ou anseios dos vários clientes; $2^{\mathrm{a}}$ ) agrupamento dos consumidores ou clientes em classes com afinidades coletivas homogêneas; e $3^{\mathrm{a}}$ ) disponibilização de produtos específicos para cada classe.

Se a empresa não trata o mercado de forma segmentada, ela deve segmentá-lo para aplicar o modelo CAC com maior eficácia. Isso por duas razões: 1) um mesmo produto pode competir em campos diferentes em cada segmento de mercado; e 2) o segmento de mercado pode ser diferente para diferente produto.

A Segmentação de mercados de consumo pode ser feita pela forma proposta por Hooley e Saunders (1996), por Kotler (2000) ou por McCarthy e Perreault (1997).

\subsection{Campos da competição e segmentação de mercado: o par produto/mercado}

Antes de decidir em qual campo competir, a empresa precisa decidir em qual mercado atuar com determinado produto. É o conceito de par produto/mercado.

Produto refere-se tanto a bens (refrigerador, sapato) como a serviços (fundo de aplicação financeira, conserto de refrigerador). No caso de grande diversidade de produtos, como nos supermercados, a empresa deve raciocinar em termos de família de produtos. 
Par produto/mercado é a entidade caracterizada simultaneamente pelo produto e pelo mercado - se o produto ou o mercado variar, o par será outro.

O modelo CAC postula que um mix de campos da competição e de campos coadjuvantes deve ser escolhido para cada par produto/mercado. O modelo é enfático - a empresa deve segmentar o mercado, definir um produto ou uma família de produtos para cada segmento de mercado e escolher os campos da competição e os coadjuvantes para cada par produto/mercado. Nesse aspecto, assemelha-se à estratégia de enfoque de Michael Porter (1980).

A estratégia do McDonald's, descrita no Quadro 2, ilustra esses conceitos.

\section{Os campos da competição dos pares produto/mercado do McDonald's}

Os principais produtos do McDonald's podem ser considerados uma única família, a de comida rápida, com pequena diversidade. Seu mercado pode ser segmentado em infantil, juvenil e adulto. Por esse prisma, portanto, compete em três pares produto/mercado.

No mercado infantil, compete no campo imagem mundo encantado. No mercado juvenil no campo imagem moderno, jovem e dinâmico. E no mercado adulto, no campo prazo de entrega. Assim, seus concorrentes são os salões de festas infantis, outros pontos de encontro de adolescentes e, para os adultos, outros restaurantes fast food.

Como é possível um produto concorrer em mercados tão distintos? É possível porque os produtos McDonald's são cuidadosamente projetados, não para agradar ao paladar, mas sim para ter baixo índice de rejeição. O paladar fica por conta dos condimentos, mostarda e ketchup, que deixam todos eles com sabor muito assemelhado.

Não são produtos que deliciam ou encantam o cliente, como pregam os profissionais de marketing. São insípidos, mas padronizados; produzidos de acordo com as melhores técnicas industriais de qualidade e produtividade (qualidade, nesse sentido, deve ser entendida como conformidade ao projeto, com baixíssima variabilidade). Ou seja, os produtos McDonald's simplesmente não devem atrapalhar, pois os campos da competição eleitos pela rede para cada segmento de mercado não são relacionados ao produto. Isso fica evidente ao se analisar suas peças publicitárias: elas nem sequer mencionam hambúrguer - enfatizam o estilo de vida moderno.

Essa colocação leva à questão: qual é o produto do McDonald's? Se no mercado infantil concorre com salões de festas infantis no campo imagem mundo encantado; e no mercado juvenil concorre com outros pontos de encontro de adolescentes no campo imagem moderno, jovem e dinâmico; seu produto não é o lanche, mas entretenimento. E usa armas adequadas para competir no campo imagem: espaços adequadamente equipados para crianças e para jovens e produtos coadjuvantes (como brindes e acesso à Internet).

Quadro 2 - Os campos da competição dos pares produto/mercado do McDonald's Fonte: Elaborado pelo autor. 


\section{UMBILICALIDADE ENTRE CAMPO DA COMPETIÇÃO E ESTRATÉGIA COMPETITIVA DE NEGÓCIO}

Há ainda três pontos que merecem discussão: a íntima relação entre estratégia competitiva de negócio e campo da competição, a quantidade de campos escolhidos pela empresa e o protagonista da competição.

\subsection{Relação biunívoca entre campo da competição e estratégia competitiva de negócio}

A configuração em 14 campos da competição facilita sobremaneira a formulação da estratégia competitiva de negócio, exatamente porque ela é válida, universal, consistente e agregada em um nível bastante adequado às aplicações do modelo CAC. Com ela, a empresa passa a ter um referencial seguro de todas as possibilidades que possui para posicionar estrategicamente seu produto e a si própria.

Um dos pilares mestres da concepção do modelo CAC é a íntima relação entre estratégia e campo da competição: a decisão sobre a estratégia competitiva de negócio consiste na definição do produto para cada mercado e na escolha de um ou dois campos principais e de um ou dois campos coadjuvantes para cada par produto/mercado.

\subsection{Quantidade de campos escolhidos pela empresa}

Já foi mencionado que a empresa geralmente compete em um ou dois campos e escolhe um ou dois campos coadjuvantes. Essa afirmação precisa ser explicada.

Para um restaurante ser competitivo, precisa ter algumas qualidades: a comida precisa ser saborosa e bem feita; o atendimento, ser cortês; o ambiente, agradável; o tempo para servir o almoço não pode ser longo (pois as pessoas precisam voltar ao trabalho); e o preço precisa ser condizente com o serviço. Se o restaurante não tiver algumas dessas qualidades, provavelmente não será bem-sucedido.

Essas qualidades são representadas pelos campos da competição e pelos coadjuvantes e valem para qualquer restaurante, desde um popular até um luxuoso. O que distingue um do outro é o mix de campos da competição e coadjuvantes.

Um restaurante popular compete em preço (procura ter preço menor do que os concorrentes) e tem como campo coadjuvante a qualidade do produto (comida). $\mathrm{O}$ sistema é self-service, de forma que não há atendimento nem tempo de espera pelo almoço. Ou seja, ele possui apenas um campo da competição e um campo coadjuvante. Já um restaurante luxuoso compete geralmente em dois campos e possui pelos menos dois campos coadjuvantes, escolhidos entre as qualidades acima mencionadas ou entre outras valorizadas pelos clientes. 


\subsection{Produto, o protagonista da competição?}

Há um conceito muito importante do modelo CAC para o qual as pessoas nem sempre estão atentas: a competição geralmente se dá entre produtos e não entre empresas.

Usualmente, se fala e se escreve que a empresa B compete com a empresa C. Em grande parte das situações, o correto é afirmar que é um produto da empresa $\mathrm{B}$ que compete com um produto da empresa $\mathrm{C}$ e não que é a empresa $\mathrm{B}$ que compete com a empresa $\mathrm{C}$. Isso porque os campos da competição mais freqüentemente escolhidos pelas empresas são os do macrocampo produto: projeto do produto, qualidade do produto ou diversidade de produtos.

Mesmo assim formulado, esse conceito está incompleto, porque a competição se dá num determinado mercado - se uma empresa não atua num mercado, seu produto não é concorrente do produto da outra empresa nesse mercado.

Conclui-se, portanto, que o correto é afirmar: é um produto da empresa $B$ que compete com um produto da empresa $C$ em num determinado mercado.

Por essa visão, o produto é o protagonista da competição.

Porém, essa visão é correta apenas parcialmente. Porque, além dos três campos do macrocampo produto, do campo preço e do campo imagem do produto e da marca, há outros nove campos da competição não relacionados diretamente ao produto: competição em condições de pagamento e em prêmio e/ou promoção, e os dos macrocampos atendimento, prazo e imagem. Para as empresas que competem nesses campos, é correto afirmar: "a empresa D compete com a empresa E num determinado mercado".

Há outra característica importante a mencionar: o campo da competição varia ao longo da vida do produto. Em cada fase do ciclo de vida de um produto há um campo mais adequado. Geralmente na fase de introdução, o campo é o de produto inovador; na fase de crescimento, competição em qualidade; e nas fases de maturidade e declínio, a competição se dá em preço.

\section{DEFINIÇÕES E CONCEITOS SOBRE ARMA DA COMPETIÇÃO}

\subsection{Definição completa de arma e de arma da competição}

Para conceituar e definir Campo e Arma da Competição foi utilizado na seção 2 o seguinte exemplo: "Sejam as seis seguintes vantagens competitivas normalmente encontradas na bibliografia: preço, propaganda, qualidade do produto, produtividade, variedade de modelos e rapidez de produção. Quais delas interessam ao cliente?" Como as armas não interessam ao cliente, concluiu-se que são propaganda, produtividade e rapidez de produção. 
Em favor da facilidade de entendimento de um conceito novo, cometeram-se duas imprecisões: 1) o conteúdo de produtividade e de rapidez de produção é muito grande para corresponder à arma segundo a acepção dada pelo modelo; e 2) produtividade e rapidez de produção não são armas, mas sim alvos da competição.

Nesta seção será esclarecida a primeira imprecisão, e na seção 11, a segunda.

Para facilitar a gestão das atividades e dos recursos da empresa (que são armas), é necessário que as atividades e recursos sejam atribuídos a um pequeno grupo de funcionários que desempenhem atividades similares, como os vendedores de uma loja, os operários de uma linha de montagem, os engenheiros e projetistas de um departamento de projeto, os gestores financeiros. Foi com essa preocupação em mente que se definiu o conteúdo que uma arma deve ter.

É fácil perceber que produtividade e rapidez de produção possuem conteúdo tão vasto que dificulta a operacionalização da arma. Assim, pela acepção do modelo CAC, produtividade e rapidez de produção são constituídos por muitas armas.

Feitas essas considerações, pode-se definir com precisão arma e arma da competição:

- Arma é qualquer atividade executada ou recurso administrado por um grupo de funcionários da empresa com atribuições homogêneas.

- Arma da competição é uma arma utilizada pela empresa para conquistar e/ou manter vantagem competitiva. Ou, mais completamente, arma da competição é qualquer atividade executada ou recurso administrado por um grupo de funcionários com atribuições homogêneas utilizado pela empresa para conquistar e/ou manter vantagem competitiva.

\subsection{Classificação das armas segundo sua natureza}

As armas são classificadas segundo sua natureza em armas de atendimento, de produção, de planejamento e de apoio ou administrativas. Essa é a classificação proposta pelo modelo geral das atividades da empresa (CONTADOR, 2001).

A grande vantagem desse agrupamento de atividades é a possibilidade da utilização de técnicas similares para qualquer tipo de empresa. As armas de produção utilizadas numa fábrica, por exemplo, são as mesmas utilizadas nas atividades produtoras de uma loja de varejo. (CONTADOR, 2001).

\subsection{Distinção entre atendimento e produção}

Todo e qualquer serviço precisa ser produzido. Essas atividades, no setor de serviços, são denominadas atividades de retaguarda ou de back office. As ativida- 
des atendedoras são as realizadas na presença física do cliente ou à distância e são denominadas de front office.

O conjunto das atividades de um atendente é constituído por quatro grupos de atividades: $\mathrm{o}$ atendimento propriamente dito, a produção do atendimento, o planejamento do atendimento e as atividades administrativas e de apoio ao atendimento.

Para o modelo CAC, o atendimento consiste simplesmente nas atividades relacionadas à recepção e ao contato; a comunicação com o cliente - é um entendimento stricto sensu.

\subsection{Armas da cooperação}

Além das armas da competição, há as armas da cooperação. Arma da cooperação é a atividade executada ou o recurso utilizado pela empresa para atuar, juntamente com outras, com a finalidade de obter beneficios comuns, como cooperação para desenvolvimento de tecnologia de processo, cooperação para compra de materiais.

\section{DETERMINAÇÃO DAS ARMAS DA COMPETIÇÃO DE UMA EMPRESA}

Um dos pontos centrais do modelo CAC é a determinação das armas da competição.

\subsection{Procedimento}

As definições de arma e de arma da competição são claras e explícitas. Mas na aplicação prática, freqüentemente surge uma dificuldade conceitual: quais atividades ou recursos são simplesmente armas e quais são armas da competição? A resposta a essa questão passa por um dos pontos centrais do modelo $\mathrm{CAC}$ - a determinação das armas da competição.

O procedimento de determinação, detalhado a seguir, contém cinco etapas:

1. Selecionar na Relação de Armas todas as atividades e recursos que têm potencial para serem armas da competição da empresa (denominada Lista de Armas versão 1).

2. Validar e complementar a Lista de armas versão 1 por meio de consulta as diversas áreas da empresa (denominada Lista de Armas versão 2).

3. Descrever o conteúdo das armas com o auxílio das áreas da empresa.

4. Identificar dentro do universo de armas da Lista de Armas versão 2, por meio da análise de conteúdo, as que têm as características necessárias para fazer 
parte do conjunto de armas da competição da empresa, conjunto denominado Lista de Armas da Competição da empresa.

5. Escolher as armas da competição que serão utilizadas em função da relevância para propiciar vantagem competitiva à empresa.

\subsection{Seleção, validação e complementação da lista das armas com base na importância}

O procedimento de seleção das armas da empresa (etapa 1) é simples: basta identificar na Relação de Armas as que são mais freqüentemente utilizadas pela empresa. Então, se elabora a Lista de Armas versão 1, que pode chegar a conter uma centena de armas. A Relação de Armas, que contém mais de duzentas armas, será disponibilizada aos interessados pelo autor. Armas específicas de cada setor não foram relacionadas. Espera-se que qualquer tipo de empresa encontre, nessa Relação de Armas, cerca de $80 \%$ a $90 \%$ das armas que utiliza.

As armas que constam dessa Relação ainda não são armas da competição da empresa. Como então identificar as armas da competição? Dois critérios são utilizados: importância e conteúdo. A importância será discutida aqui, o conteúdo, na próxima subseção.

Depois é necessário validar e complementar essa lista (etapa 2). Validar porque raramente a pessoa que fez a seleção conhece todas as atividades realizadas e todos os recursos utilizados na empresa. Complementar porque a Relação de Armas não é suficientemente completa no sentido de conter todas as armas de qualquer tipo de empresa.

Para validar e complementar, basta perguntar, e obter respostas de cada gerente ou chefe de seção se constam da Lista de Armas versão 1: 1) as atividades mais importantes da sua área de responsabilidade, as mais freqüentemente realizadas e/ou as mais onerosas em termos de pessoas e equipamentos; 2) os recursos mais importantes da sua área de responsabilidade, os mais freqüentemente utilizados e/ou os mais onerosos em termos financeiros; e 3) as armas importantes que sua área de responsabilidade não utiliza mas que deveria utilizar. Esse método é baseado na premissa de que uma arma da competição tem pelo menos uma dessas características.

Poder-se-ia usar outro método: perguntar para cada gerente ou chefe de seção qual é, entre as atividades executadas na sua área, a mais importante e qual é, entre os recursos utilizados, o mais importante.

Pela validação e complementação da Lista versão 1 e por meio de inquérito em todas as áreas, obtém-se a Lista de Armas versão 2, que contempla as armas mais importantes, mais freqüentemente utilizadas e as mais onerosas da empresa. Natural- 
mente, nessa Lista há armas das cinco classes: atendimento, produção, planejamento, administrativas e de cooperação.

A experiência na aplicação do modelo CAC mostra que a Lista de Armas versão 2 deve conter de 60 a 80 armas. A única razão dessa restrição é a redução do trabalho de análise, como será discutido na próxima subseção.

\subsection{Determinação do conjunto das armas da competição com base no seu conteúdo}

A natureza e a importância de uma atividade ou um recurso, por si sós, não são critérios suficientes para determinar se uma arma deve ou não fazer parte das armas da competição da empresa - é necessário levar em consideração também seu conteúdo.

Para esclarecer esse conceito, tome-se, por exemplo, a atividade contabilidade. Como é uma atividade, é uma arma. E é, sem dúvida, uma atividade muito importante, independentemente da sua obrigatoriedade fiscal. Mas a contabilidade tradicional não é uma arma da competição porque não tem conteúdo estratégico, ela não proporciona vantagem competitiva à empresa. Entretanto, poderá ser uma arma da competição para determinada empresa se ela abranger certos conteúdos. Para descrever o conteúdo de cada arma que consta da Lista de Armas versão 2 deve-se recorrer às áreas responsáveis por elas.

Cumprida essa terceira etapa, parte-se para a identificação daquelas armas que farão parte do conjunto das armas da competição da empresa, o que é feito por meio da análise de conteúdo (etapa 4): se uma atividade ou recurso tiver conteúdo estratégico, a arma correspondente será considerada arma da competição.

Assim é determinado o conjunto de armas da competição da empresa, denominado Lista de Armas da Competição da empresa.

A experiência na aplicação do modelo evidencia que um conjunto de 40 a 50 armas da competição consegue representar muito bem as atividades e os recursos estratégicos da empresa. Uma quantidade maior do que 50 armas aumentará em muito o trabalho de análise das estratégias competitivas da empresa - pois a quantidade de comparações a serem feitas na matriz de priorização das armas (vide 10.2) é proporcional ao quadrado do número de armas.

Essas quatro etapas evidenciam que a natureza, a importância e o conteúdo de uma atividade ou de um recurso são os critérios para determinar se ela ou ele deve fazer parte do conjunto das armas da competição da empresa.

Mas quais dessas armas da competição serão utilizadas pela empresa para competir num campo? A resposta está na próxima seção. 


\section{CLASSIFICAÇÃO DAS ARMAS SEGUNDO SUA RELEVÂNCIA PARA A COMPETIÇÃO DA EMPRESA}

Outro ponto central do modelo CAC é a determinação das armas que são relevantes para propiciar competitividade à empresa.

\subsection{Conceito de relevância e definição de arma relevante, semi-relevante e irrelevante}

Entenda-se, para facilitar a explicação, o conjunto das armas da competição como sendo o arsenal da empresa. No campo militar, do arsenal são retiradas as armas para um combate. E, de acordo com o tipo de combate, são retiradas as armas apropriadas. Todas são armas de combate (aqui denominadas armas da competição), mas só algumas serão utilizadas - e, o que determina quais serão utilizadas é o tipo do combate.

Analogamente, do arsenal das armas da competição da empresa são retiradas as armas para competir em determinado campo. A relevância da arma para a competitividade (mais especificamente, para os campos da competição) da empresa é o critério para identificar se uma arma da competição deve ou não ser utilizada para competir num campo. Ou seja, é o campo da competição que determina se uma arma da competição da empresa é ou não relevante para a competição.

Pelo critério de relevância, as armas da competição da empresa são classificadas em armas relevantes, semi-relevantes e irrelevantes para cada campo da competição.

Arma relevante é uma arma pertencente ao conjunto das armas da competição da empresa que proporciona elevada vantagem competitiva a ela no campo escolhido para competir. É uma arma necessária para a competição num determinado campo da competição. Pela tese do modelo CAC, é a alta intensidade das armas relevantes que dá vantagem competitiva à empresa. Portanto, é justificável um elevado investimento para a obtenção de expressiva competência. O conceito de intensidade da arma será dado no segundo artigo.

Arma semi-relevante é uma arma pertencente ao conjunto das armas da competição da empresa que proporciona mediana vantagem competitiva a ela no seu campo da competição. É uma arma de importância intermediária entre as armas relevantes e as irrelevantes para o campo da competição e que deve ter intensidade média, não justificando alto investimento.

Arma irrelevante é uma arma pertencente ao conjunto das armas da competição da empresa que não propicia vantagem competitiva a ela nem no seu campo da competição nem no seu campo coadjuvante. É uma arma da competição inútil para 
uma determinada estratégia competitiva de negócio e que deve ter baixa intensidade, exigindo pequeno investimento.

Uma arma relevante para um campo da competição pode ser irrelevante para outro e semi-relevante para um terceiro. Uma arma irrelevante para um campo não pode ser excluída da análise da empresa, pois ela faz parte do conjunto das suas armas da competição.

Para encerrar esta seção, é oportuno relacionar arma relevante à competência essencial. Competência essencial, na acepção dada por Hamel e Prahalad (1995) um conjunto de habilidades e tecnologias que permite a uma empresa oferecer um determinado benefício aos clientes - tem o mesmo significado de arma relevante, porém mais denso e abrangente. Ou seja, uma competência essencial contém um conjunto de armas relevantes.

\subsection{Método para determinar a relevância das armas da competição: matriz de priorização das armas e índice de Nihans}

A matriz de priorização das armas é uma matriz quadrada, contendo todas as armas da competição da empresa (contidas na Lista das Armas da Competição da empresa) nas linhas e todas nas colunas. A classificação parte da comparação de cada arma da linha com todas as armas das colunas e da atribuição, em cada célula da matriz, de pesos que variam de +2 a -2 . Para construir a matriz, o responsável pela classificação deve responder, para cada arma, a seguinte pergunta: "Para competir neste campo (campo para o qual a matriz está sendo construída), a arma da linha é mais ou menos relevante do que a arma da coluna?". Se for muito mais relevante, atribuir peso 2. Se for mais relevante, atribuir peso 1. Se for de mesma relevância, atribuir peso 0 . Se for menos relevante, atribuir peso (-1). E se for muito menos relevante, atribuir peso (-2).

O valor da soma dos pesos das células de cada linha ordena as armas segundo a relevância que possui para o respectivo campo da competição e gera o ranking de relevância. A matriz é diagonalmente simétrica, com sinal trocado, uma matriz de soma nula.

O índice de Nihans é utilizado para separar um conjunto homogêneo de itens quantificados, sendo os mais importantes (Classe A) aqueles maiores que o índice e menos importantes (Classe Não-A) aqueles inferiores ao índice. A aplicação do índice sobre a Classe Não-A propicia, analogamente, a identificação dos itens menos importantes (Classe $\mathrm{C}$, aqueles menores que o índice) e dos itens de mediana importância (Classe B, aqueles maiores que o índice). O índice de Nihans, aplicado para a identificação das armas relevantes, das semi-relevantes e das irrelevantes, é calculado por: 


$$
N=\frac{\sum(s p)^{2}}{\sum(s p)}
$$

em que (sp) é a soma dos pesos de cada linha (arma). As armas relevantes, as semi-relevantes e as armas irrelevantes são as pertencentes, respectivamente, às Classes A, B e C.

O procedimento desse método está descrito em De Sordi e Contador (2005).

\subsection{Ranking de relevância e sensibilidade do método a enganos de avaliação}

O método para classificar as armas segundo sua relevância para a competição da empresa tem duas vantagens importantes: primeira, mais do que classificar, ele estabelece um ranking quantificado; segunda, ele tem baixa sensibilidade a enganos de avaliação dos pesos.

A soma de uma linha da matriz de priorização das armas mostra o valor dos pontos da respectiva arma, o que permite saber quão mais relevante é uma arma em relação à outra.

Havendo um ranking de relevância das armas, é possível separá-las em três classes sem usar o índice de Nihans. Para tanto, basta construir a matriz de priorização das armas, ordená-la decrescentemente em relação à coluna da soma dos pesos e separar as armas nas três classes. A Classe A será constituída pelo primeiro quarto ou primeiro terço das armas, a Classe B pelo segundo quarto ou segundo terço das armas, e a Classe $\mathrm{C}$ pelas restantes.

É preferível não usar o índice de Nihans, pois o procedimento fica mais livre e permite a consideração de outros fatores para a determinação dos limites entre as três classes.

Apesar da formalidade do método, a classificação resulta da avaliação subjetiva dos pesos de cada arma, sujeita portanto a enganos e vieses. Para minimizar os efeitos da subjetividade, o método deve ser aplicado por um grupo de pessoas que conheçam bem as atividades da empresa. Assim, a classificação final deve resultar ou do consenso do grupo, ou da escolha pela maioria, ou da média das opiniões, ou da aplicação de um processo Delphi.

\subsection{Método expedito para determinar a relevância das armas da competição}

O método expedito para determinar a relevância das armas é muito mais simples que o anterior, mas não possibilita a obtenção do ranking de relevância das armas. Entretanto, é aplicável quando se deseja apenas a separação entre essas três classes de armas. 
O método expedito consiste simplesmente em identificar, dentro da Lista de Armas da empresa, aquelas que dão vantagem competitiva no campo em análise. A experiência mostra que as armas relevantes são um terço ou um quatro das armas da Lista e que as semi-relevantes são também um terço ou um quarto delas.

\subsection{Verificação do conjunto das armas da competição e da relevância de cada uma}

Para dar confiança aos resultados desses dois procedimentos, eles devem ser validados por um grupo maior de pessoas. Assim, uma comissão deve ser formada. Nessa verificação, os membros dessa comissão devem considerar outros fatores, inclusive os que eventualmente tenham sido relegados ao segundo plano durante a determinação do conjunto das armas relevantes e durante a atribuição de pesos para classificar as armas segundo sua relevância.

\section{ALVO DA ARMA}

Além de campo da competição e arma da competição, o modelo CAC possui uma terceira entidade: o alvo da arma.

\subsection{Conceitos e definição de alvo da arma}

Para explicar o conceito de alvo da arma, é conveniente recorrer a um exemplo. Seja a arma programação da produção. Se a empresa decidiu competir em preço, precisa ter alta produtividade para obter baixo custo, e o programa de produção deve evitar ao máximo as paradas de máquinas e de pessoal (pois horas paradas oneram os custos), o que provavelmente obrigará o produto a sofrer algumas paradas. Se a empresa decidiu competir em prazo de entrega, precisa ter alta velocidade de produção, e o programa de produção deve evitar ao máximo as paradas do produto, o que provavelmente obrigará as máquinas e o pessoal a sofrer algumas paradas. Essas duas situações decorrem do fato de ser difícil balancear os tempos das operações - máquinas e pessoal com mínimas paradas provavelmente acarretarão paradas no produto, e vice-versa. É fácil de entender que o programa de produção que tem por objetivo aumentar a produtividade é diferente daquele cujo objetivo é aumentar a velocidade. Ou seja, a mesma arma, programação da produção, gera dois programas de produção diferentes. E por quê? Porque ela tem objetivos diferentes.

Desse exemplo, podem-se extrair dois conceitos: 1) uma mesma arma proporciona soluções diferentes dependendo do objetivo; e 2) o objetivo varia em função do campo da competição. Deduz-se que o mencionado objetivo é uma outra entida- 
de, diferente de arma da competição e de campo da competição. Essa entidade foi batizada de alvo da arma.

Pode-se então definir: alvo da arma é o objetivo de uma arma da competição, o objetivo que uma arma da competição deve mirar. Serve para canalizar e orientar os esforços de uma arma da competição.

Note-se que a definição menciona arma da competição e não simplesmente arma. Essa restrição tem uma razão de ser: não obstante a aplicação de qualquer arma sempre ter um objetivo, o interesse do modelo CAC está apenas nas armas da competição.

\subsection{Associação entre alvos das armas e campos da competição}

No exemplo da programação da produção havia dois objetivos excludentes: minimizar o custo ou aumentar a velocidade. O primeiro é fundamental para a competição em preço; o segundo, para a competição em prazo de entrega do produto.

Uma conclusão: há um alvo das armas associado a cada campo da competição. Essa associação entre alvos das armas e campos da competição é regida por dois condicionantes: 1) o alvo é determinado pelo campo da competição; e 2) cada campo da competição tem um alvo das armas a ele associado. Isso tem as implicações explicitadas a seguir.

Foi mencionado que uma mesma arma serve para competir em mais de um campo. Com a introdução do conceito de alvo, é necessário complementar essa afirmação: uma mesma arma serve para competir em mais de um campo, mas terá alvos diferentes.

Foi mencionado que para competir em um campo são necessárias várias armas. Com a introdução do conceito de alvo, é necessário complementar essa afirmação: para competir em um campo são necessárias várias armas da competição que terão idêntico alvo.

A importância do alvo é muito grande para o modelo de Campos e Armas da Competição por duas razões:

O alvo é o elo entre uma arma da competição e um campo da competição.

As armas da competição da empresa devem mirar o alvo do campo da competição escolhido por ela. 


\subsection{O alvo das armas da competição de cada campo da competição}

O Quadro 3 apresenta os alvos das armas relativos aos campos da competição e aos campos coadjuvantes.

\begin{tabular}{|c|c|c|}
\hline \multicolumn{3}{|c|}{ Alvos das armas associados a cada campo da competição } \\
\hline Campo da competição & $\begin{array}{l}\text { Alvo relativo ao campo } \\
\text { da competição }\end{array}$ & $\begin{array}{l}\text { Alvo relativo ao campo } \\
\text { coadjuvante }\end{array}$ \\
\hline $\begin{array}{l}\text { Competição em preço } \\
\text { 1. em preço propriamente dito } \\
\text { 2. em condições de pagamento } \\
\text { 3. em prêmio e/ou promoção }\end{array}$ & $\begin{array}{l}\text { Produtividade } \\
\text { Produtividade } \\
\text { Produtividade }\end{array}$ & $\begin{array}{l}\text { Produtividade } \\
\text { Produtividade } \\
\text { Produtividade }\end{array}$ \\
\hline $\begin{array}{l}\text { Competição em produto } \\
\text { 4. em projeto do produto } \\
\text { 5. em qualidade do produto } \\
\text { 6. em diversidade de produtos }\end{array}$ & $\begin{array}{l}\text { Novidade } \\
\text { Qualidade no processo } \\
\text { Flexibilidade }\end{array}$ & $\begin{array}{l}\text { Diversos } \\
\text { Qualidade no processo } \\
\text { Flexibilidade }\end{array}$ \\
\hline $\begin{array}{l}\text { Competição em atendimento } \\
\text { 7. em acesso ao atendimento } \\
\text { 8. em projeto do atendimento } \\
\text { 9. em qualidade do atendimento }\end{array}$ & $\begin{array}{l}\text { Acessibilidade } \\
\text { Novidade } \\
\text { Qualidade no processo }\end{array}$ & $\begin{array}{l}\text { Acessibilidade } \\
\text { Diversos } \\
\text { Qualidade no processo }\end{array}$ \\
\hline $\begin{array}{l}\text { Competição em prazo } \\
\text { 10. em prazo de entrega do produto } \\
\text { 11. em prazo de atendimento }\end{array}$ & $\begin{array}{l}\text { Velocidade } \\
\text { Velocidade }\end{array}$ & $\begin{array}{l}\text { Velocidade } \\
\text { Velocidade }\end{array}$ \\
\hline $\begin{array}{l}\text { Competição em imagem } \\
\text { 12. do produto e da marca } \\
\text { 13. de empresa confiável } \\
\text { 14. em responsabilidade social }\end{array}$ & $\begin{array}{l}\text { Desejabilidade } \\
\text { Confiabilidade } \\
\text { Responsabilidade social }\end{array}$ & $\begin{array}{l}\text { Confiabilidade } \\
\text { Confiabilidade } \\
\text { Responsabilidade social }\end{array}$ \\
\hline
\end{tabular}

Quadro 3 - Alvos das armas associados a cada campo da competição

Fonte: Elaborado pelo autor.

\subsection{Alvo coadjuvante e coerência na nomenclatura dos alvos}

Alvo coadjuvante é uma modulação no alvo da arma para melhor objetivá-la, é um objetivo secundário e complementar que a arma deve mirar para melhor canalizar e orientar sua utilização. Ele é determinado pelo campo coadjuvante ou pela aplicação da arma e pode ser qualquer um dos nove alvos das armas ou um diferente. É pela fixação dos alvos das armas e dos alvos coadjuvantes que a empresa define com precisão o objetivo de uma arma da competição.

Por uma questão de coerência lingüística, os alvos devem ser representados por palavras formadas pelo sufixo nominal -dade. Celso Cunha (1976) ensina que, 
na língua portuguesa, "substantivos derivados de adjetivos, geralmente nomes abstratos, indicam qualidade, propriedade, estado ou modo de ser". Esses substantivos derivados de adjetivos são formados pelo acréscimo de sufixos. Assim, para batizar os alvos, deve-se acrescentar o sufixo -dade ao adjetivo: produtivo > produtividade; flexível $>$ flexibilidade. Celso Cunha (1976) observa que "antes de receberem o sufixo -dade, os adjetivos terminados em - $a z,-i z$, $-o z$ e -vel retomam a forma latina em $-a c(i),-i c(i),-o c(i)$ e $-b i l(i)$ : sagaz $>$ sagacidade, feliz $>$ felicidade, feroz $>$ ferocidade, amável > amabilidade".

Devido a essa coerência da nomenclatura, fica fácil reconhecer um alvo, evitando confundi-lo com arma - basta ver se a palavra termina em - dade. Deve-se mencionar que a palavra qualidade não é formada por sufixação, uma vez que vem diretamente da palavra latina qualitas/tis.

\section{OS CONDICIONANTES DA COMPETITIVIDADE}

Quais são as causas da competitividade? Quais são as condições para a empresa ser competitiva? Como uma empresa deve agir para se tornar mais competitiva?

Há unanimidade de pensamento quanto à primeira causa - possuir um produto adequado ao mercado a que se destina. Mas daí para frente há divergências.

Pela Teoria da Competitividade, uma empresa é mais competitiva (tem melhor resultado) porque tem pelo menos uma vantagem competitiva em relação às suas concorrentes. De um modo geral na literatura de estratégia, é mencionado produto adequado ao mercado, sendo comum a ênfase sobre a necessidade de o produto conter inovações.

O modelo de Campos e Armas da Competição coloca outras três condições para a empresa ser competitiva, ou seja, quatro são os condicionantes da competitividade:

1. Produto adequado ao mercado a que se destina.

2. Escolha adequada dos campos da competição e dos coadjuvantes para cada par produto/mercado.

3. Uso adequado das armas da competição, o que significa identificar as armas que são relevantes, semi-relevantes e irrelevantes para os campos da competição e para os coadjuvantes e definir a intensidade dessas armas.

4. Alinhamento das armas aos campos da competição e aos coadjuvantes.

Esses condicionantes decorrem da tese do modelo de Campos e Armas da Competição exposta no início do artigo e foram validados, como se confere no segundo artigo da série. 
José Celso Contador

\title{
CONCEPTS ON THE FIELDS AND WEAPONS OF THE COMPETITION MODEL
}

\begin{abstract}
Up to now, the Fields and Weapons of the Competition Model has been publicized as a theoretical framework for many studies and, as such, it has appeared in a fragmented manner. Due to the level of consolidation the model has achieved, now is the time to present it integrally, so as to expose it to the appreciation of the scientific community dedicated to Corporate Strategy. Belonging to the Competitiveness theory and having scientific validity, the model is both qualitative and quantitative, and therefore presents some advantages over Porter's model, as well as over the RBV and the Balanced Scorecard models. A simple idea has originated it: according to the customer's interest, separating the so-called competitive advantages, so as to sort out those that interest him/her from those that do not. The first group consists of the fields of the competition; the latter corresponds to the weapons of the competition. The fields of the competition relate to the business' competitive strategy, and the weapons of the competition related to the operational competitive strategies. This is the first of a series of three articles.
\end{abstract}

Keywords: Competitive Strategy. Field of the Competition. Weapon of the Competition. Business Competitive Strategy. Operational Competitive Strategy.

\section{REFERÊNCIAS}

ANSOFF, I. The new corporate strategy. John Wiley \& Sons, 1988.

BARNEY, J. Strategic factor markets: expectations, luck and business strategy. Management Science, v. 32, n. 10, p. 1231-1241, 1986a.

. Organizational culture: can it be a source of sustained competitive advantage? Academy of Management Review, v. 11, n. 3, p. 656-665, $1986 \mathrm{~b}$.

. Firm resources and sustained competitive advantage. Journal of Management, Bloomington, v.17, n. 1, p. 99-120, mar. 1991.

Resource-based theories of competitive advantage: a ten year retrospective on the resource-based view. Journal of Management, New York, v.27, n.6, nov/ dec. 2001. 
CONTADOR, J. Celso. Campos da competição. Revista de Administração (USP), São Paulo, v. 30, n. 1, p. 32-45, jan/mar. 1995a.

. Armas da competição. Revista de Administração (USP), São Paulo, v. $\overline{30, \text { n. } 2}, 1995$ b.

1996.

Modelo para aumentar a competitividade industrial. São Paulo: Blücher,

Gestão de operações. 2. ed. São Paulo: Edgard Blücher, 1998, 592 p.

. Modelo geral das atividades da empresa. Revista Gestão \& Produção

(UFSCar), São Carlos, v. 8, n. 3, p. 219-236, dez. 2001.

CUNHA, Celso. Gramática do Português contemporâneo. 6. ed. Belo Horizonte: Bernardo Álvares, 1976.

DE SORDI, J. O.; CONTADOR, J. C. Integração dos sistemas de informação à estratégia da organização por meio do modelo de campos e armas da competição. Revista de Administração, São Paulo, v. 40, n. 2, p. 123-135, abr/jun. 2005.

HAMEL, G.; PRAHALAD, C. K. Competindo pelo futuro. Rio de Janeiro: Campus, 1995.

HOOLEY, G; SAUNDERS, J. Posicionamento competitivo. São Paulo: Makron Books, 1996.

KAPLAN, R. S.; NORTON, D. P. The balanced scorecard - Measures that drive performance. Harvard Business Review, Boston, v. 70, n. 1, p. 71-79, jan/feb. 1992.

Putting the balanced scorecard to work. Harvard Business Review, Boston, v. 71, n. 5, p. 134-142, sep/oct. 1993.

. Using the balanced scorecard as a strategic management system. Harvard Business Review, Boston, v. 74, n. 1, p. 75-85, jan/feb. 1996.

A estratégia em ação. Rio de Janeiro: Campus, 1997.

KOTLER, P. Administração de marketing. São Paulo: Prentice Hall, 2000. 
KROGH, G.; ROSS, J. A perspective on knowledge, competence and strategy. Personal Review, Farnborough, v. 24, n. 3, p. 56-76, june 1995.

MARKIDES, C. C. A dynamic view of strategy. Sloan Management Review, 1999.

McCARTHY, J.; PERREAULT, W. Marketing essencial. São Paulo: Atlas, 1997.

MINTZBERG, H.; AHLSTRAND, B.; LAMPEL, J. Safári de estratégia. Porto Alegre: Bookman, 2000.

NAGEL, E.; NEWMAN, J. R. Gödel's proof. New York: New York University Press, 1958.

PETERAF, M.A. The cornerstones of competitive advantage: a resource-based view. Strategic Management Journal, West Lafayette, Indiana, USA Chichester, v. 14, n. 3, 1993.

PORTER, M. E. Competitive Strategy. New York: Free Press, 1980.

PRAHALAD, C. K.; HAMEL, G. Strategy as a field of study: why search for a new paradigm? Strategic Management Journal, West Lafayette, Indiana, USA, n. $15,1994$.

SMITH, W. Product differentiation and market segmentation as marketing strategies. Journal of Marketing, v. 21, p. 3-8, jul., 1956.

WHITTINGTON, Richard. What is strategy - and does it matter? London: Thomson Learning, 2001. 